\title{
KHẢO SÁT NỒNG ĐỘ TESTOSTERONE Ở NAM GIỚI TỬ 50 - 60 TUỔI
}

Nguyễn Ngoc Sơn ${ }^{1}$, Đỗ Trung Quân $n^{1,2}$

1. Truờng Đại học Y Hà Nội

2. Bệnh viện Bạch Mai

DOI: $10.47122 / v j d e .2020 .41 .3$

\section{ABSTRACT \\ Survey of blood testosterone levels in men aged 50 - 60 years old}

Objective: Survey of blood total testosterone levels in men aged 50 - 60 years old. Subject and methods: The crosssectional descriptive study including 79 men who were examined at Bach Mai Hospital from December 2019 to June 2020. Results and conclusion: In the study group, the concentration of total blood testosterone of $50-60$ years old men was $16.64 \pm 6.90 \mathrm{nmol} / \mathrm{l}$. Total blood testosterone levels were inversely correlated with serum triglyceride levels and serum LDL-C levels, BMI, waist circumference and waist/hip ratio (WHR). There were no statistically significant correlation between total blood testosterone levels and total cholesterol and HDL-C levels. In this study, statistically significant differences were not found in the testosterone levels of the high blood pressure, alcohol and smoking groups.

Keywords: Testosterone, men aged $50-60$ years old.

\section{TÓM TẮT}

Muc tiêu: Khảo sát nồng độ Testosterone toàn phần ở nam giớitrong độ tuổi từ $50-60$ tuổi. Đối tự̛ng và phương pháp nghiên cúu: Nghiên cứu mô tả cắt ngang gồm 79 bệnh nhân đi khám bệnh tại Bệnh viện Bạch Mai từ tháng 12/2019 đến tháng 06/2020. Kết quả và kết luận: Nồng độ testosterone toàn phần ở nhóm đối tượng nghiên cứu là nam giới từ $50-60$ tuổi là $16.64 \pm 6.90 \mathrm{nmol} / \mathrm{l}$. Nồng độ testosterone máu toàn phần tương quan nghịch biến với nồng độ Triglycerid và nồng độ $\mathrm{LDL}-\mathrm{C}, \mathrm{BMI}$, vòng eo và chỉ số eo/hông (WHR). Chưa thấy sự tương quan có ý nghĩa thống kê giữa nồng độ testosterone máu toàn phần với Cholesterol toàn phần và HDL-C. Trong nghiên cứu này, chưa tìm thấy sự khác biệt có ý nghĩa thống kê về nồng độ testosterone của các nhóm có THA, uống rượu và hút thuốc.

Tù khóa: Testosterone, nam giới tù 50 đến 60 tuổi.

Chịu trách nhiệm chính: Đỗ Trung Quân

Ngày nhận bài: 15/8/2020

Ngày phản biện khoa học: 11/9/2020

Ngày duyệt bài: 10/10/2020

Email: dotrungquandiab@yahoo.com

Điện thoại: 0985111666

\section{1. ĐĂT VẤN ĐỀ}

Testosterone là hormone sinh dục nam có bản chất là steroid được bài tiết chủ yếu bởi tế bào Leydig của tinh hoàn (trên 95\%). Đây là hormone có vai trò quan trọng nhất trong chức năng sinh sản của nam giới. Có rất nhiều các tác dụng sinh học của testosterone đã được chứng minh. Testosterone rất cần thiết cho sự phát triển và biệt hóa cơ quan sinh dục trong và cơ quan sinh dục ngoài của nam giới trong suốt quá trình phát triển của bào thai. Trong giai đoạn dậy thì, sự tăng trưởng của bìu, mào tinh, ống dẫn tinh, túi tinh, tuyến tiền liệt và dương vật cũng phụ thuộc vào vai trò rất lớn của testosterone.

Testosterone kích thích sự tăng trưởng của hệ cơ xương, phì đại niêm mạc và phát triển thanh quản làm cho giọng nói của nam giới trở nên trầm hơn và xuất hiện hiện tượng "vỡ giọng" ở tuổi dậy thì. Lông sinh dục, phát triển râu, ria mép và lông ở ngực bụng, lung cũng như hoạt động của các tuyến bã nhờn. Các tác động khác bao gồm kích thích tạo hồng cầu và các thay đổi hành vi xã hội khác nhau giữa nam giới và nữ giới [1]. Ngày này, tuổi thọ dân số nói chung ngày càng gia tăng, tại Nhật Bản là 84,1 tuổi (theo WHO), tại Việt Nam là 73,6 tuồi, trong đó tuổi thọ trung 
bình của nam giới là 71,0 tuổi (theo báo cáo kết quả của cuộc Tổng điều tra dân số và nhà ở năm 2019 của Tổng cục Thống kê Việt Nam). Chính vì vậy, testosterone vẫn có vai trò quan trọng ở sau tuổi 50 kể cả về chức năng tình dục lẫn chức năng thể chất. Tuy nhiên do sự phát triển của kinh tế xã hội làm thay đổi lối sống, sinh hoạt, chế độ ăn uống, luyện tập, rượu bia, thuốc lá, các loại thuốc, mô hình bệnh tật,... đã làm ảnh hưởng đến những đối tượng trên 50 tuổi, gây tác động đến nồng độ testosterone ở đối tượng này. Trước đây, testosterone chủ yếu được quan tâm trong các bệnh lý về suy sinh dục với các triệu chứng như: giảm ham muốn tình dục, rối loạn cương dương [2]. Gần đây có nhiều nghiên cứu chứng minh ảnh hưởng của testosterone đến nhiều cơ quan khác trên cơ thể, gây ảnh hưởng đến sức khỏe của nam giới, đặc biệt là nam giới trên 50 tuổi. Testosterone giảm làm giảm khối cơ, tăng khối lượng mỡ, đặc biệt là mỡ tạng. Khi sự tích lũy mỡ tạng tăng sẽ làm tăng tổng hợp acid béo dẫn tới tình trạng đề kháng Insulin, rối loạn lipid máu đây là nguyên nhân chính gây ra hội chứng chuyển hóa ở nam giới. Ngược lại, trên những bệnh nhân có hội chứng chuyển hóa thường có tình trạng béo phì. Tình trạng này làm tăng sản xuất các cytokine viêm và tăng chuyển testosterone thành estradiol ở mô mỡ, khi nồng độ estradiol cao sẽ gây ức chế tuyến yên sản xuất $\mathrm{LH}, \mathrm{FSH}$ do đó làm giảm sản xuất testosterone.

Hiện nay ở Việt Nam, chưa có nghiên cứu nào về nồng độ testosterone máu ở nam giới từ 50 - 60 tuổi. Vì vậy, chúng tôi tiến hành nghiên cứu này với mục tiêu: Khảo sát nồng độ testosterone máu ở nam giới tù 50 60 tuổi.

\section{2. ĐỐI TƯợng VÀ PHƯƠNG PHÁP NGHIÊN CÚ'U}

2.1. Đối tượng nghiên cứu: Nghiên cứu được thực hiện tại khoa Khám bệnh và khoa Khám bệnh theo yêu cầu Bệnh viện Bạch Mai từ tháng $12 / 2019$ dến tháng $06 / 2020$, gồm 78 nam giới trong độ tuổi từ $50-60$ tuổi đi khám sức khỏe và được loại trừ các bệnh lý suy sinh dục nguyên phát hoặc thứ phát. các bệnh cấp tính, nặng: nhiễm trùng, xơ gan, suy thận nặng, nhiềm HIV, đang dùng corticoid, lợi tiểu kháng aldosterone..; có tiền sử hoặc đang mắc các bệnh nội tiết như bệnh lý tuyến giáp, tuyến yên, đái tháo đường,... và đang dùng các thuốc hay thực phẩm chức năng có chứa testosterone hoặc gây ảnh hưởng đến nồng độ testosterone máu.

\subsection{Phương pháp nghiên cứu}

Nghiên cứu tiến cứu, mô tả cắt ngang. Tất cả nam giới 50 -60 tuổi đủ tiêu chuẩn tham gia nghiên cứu, được hỏi bệnh, khám lâm sàng và làm các xét nghiệm testosterone máu $\mathrm{TP}$ và các xét nghiệm cần thiết. Số liệu thu thập được ghi theo một mẫu bệnh án nghiên cứu thống nhất.

Nồng độ testosterone máu toàn phần được định lượng bằng phương pháp điện hóa phát quang bằng máy Cobas E601. Đơn vị nmol/1.

- Các biến số và chỉ số nghiên cứu gồm:

Nhóm biến số về nồng độ testosterone máu: nồng độ testosterone máu toàn phần.

Nhóm biến số về các yếu tố liên quan đến nồng độ testosterone máu: tuổi, hút thuốc, uống rượu, THA, bộ câu hỏi ADAM, BMI, vòng bụng, tỉ số vòng bụng/hông (WHR), Nồng độ Cholesterol máu, Triglycerid máu, HDL-C, LDL-C.

- Số liệu được xử lý theo phương pháp thống kê $\mathrm{y}$ học bằng phần mềm SPSS 20.0. 


\section{KẾT QUẢ NGHIÊN CỨU}

\section{1. Đặc điểm chung của nhóm bệnh nhân nghiên cứu.}

Bảng 1. Tuổi của nhóm đối tượng nghiên cứu.

\section{Tuổi trung bình$$
\overline{\mathrm{X}} \pm \mathrm{SD}
$$$$
(\min -\max )
$$

\section{Giá trị}

$$
54,90 \pm 3,49
$$$$
(50 \div 60)
$$

Độ tuổi trung bình của nhóm nghiên cứu là 54,90 $\pm 3,49$ tuổi.

Bảng 2. Tỷ lệ hút thuốc (thuốc lá, thuốc lào) và uống rượu.

\begin{tabular}{|c|c|c|c|}
\hline & Có & Không & Tổng \\
\hline $\begin{array}{c}\text { Hút thuốc lá } \\
\text { n,\% }\end{array}$ & 44 & 35 & 79 \\
\hline $\begin{array}{c}\text { Uống rượu } \\
\text { n,\% }\end{array}$ & $55,7 \%$ & $44,3 \%$ & 79 \\
\hline
\end{tabular}

Bảng 3. Tỷ lệ THA và không THA của nhóm đối tượng.

\begin{tabular}{|c|c|c|c|}
\hline & THA & Không THA & Tổng \\
\hline $\mathbf{n}, \boldsymbol{\%}$ & 23 & 56 & 79 \\
& $29,1 \%$ & $70,9 \%$ & \multirow{2}{*}{ \% } \\
\hline
\end{tabular}

Bảng 4. Tỷ lệ nam giới có bộ câu hỏi $\mathrm{ADAM}(+)$ trong nhóm đối tượng nghiên cứu

\begin{tabular}{|c|c|c|c|}
\hline & ADAM (+) & ADAM (-) & Tổng \\
\hline $\mathbf{n}, \%$ & 66 & 13 & 79 \\
& $83,5 \%$ & $16,5 \%$ & $100 \%$ \\
\hline
\end{tabular}

Có 83,5\% số nam giới trong nhóm đối tượng nghiên cứu có triệu chứng gợi ý suy sinh dục nam với bộ câu hỏi ADAM (+).

Bảng 5. BMI, vòng eo (tỷ lệ béo bụng), chỉ số eo/ hông

\begin{tabular}{|c|c|c|c|}
\hline & $\mathbf{n}$ & Trung bình \pm SD & Tỷ lệ (\%) \\
\hline BMI $\left(\mathrm{kg} / \mathrm{m}^{2}\right)$ & 79 & $22,6 \pm 2,8$ & 100 \\
\hline$<18,5$ & 04 & & 5,1 \\
\hline $18,5-22,9$ & 41 & & 51,9 \\
\hline$>23$ & 34 & & 43,0 \\
\hline Vòng eo (cm) & 77 & $83,10 \pm 8,11$ & \\
\hline$<90 \mathrm{~cm}$ & 59 & & 74,7 \\
\hline$\geq 90 \mathrm{~cm}$ & 20 & & 25,3 \\
\hline Vòng hông (cm) & & $89,53 \pm 6,22$ & \\
\hline \multicolumn{4}{|l|}{ Tỷ số eo/hông } \\
\hline$\leq 0.9$ & 22 & & 27,8 \\
\hline$>0,9$ & 57 & & 72,2 \\
\hline
\end{tabular}


Nhận xét: BMI trung bình của nhóm nghiên cứu là $22,6 \pm 2,8 \mathrm{~kg} / \mathrm{m}^{2}$, trong đó chủ yếu nam giới có $\mathrm{BMI}$ trong giới hạn bình thường là $51,9 \%$, nam giới có có chỉ số $\mathrm{BMI}$ trong khoảng thừa cân béo phì là 43,0\%.

Đối tượng có chỉ số BMI thấp nhất là 16,5 , cao nhất là 29,4 . Vòng eo trung bình của nhóm đối tượng nghiên cứu là $83,10 \pm 8,11 \mathrm{~cm}$, trong đó số lượng nam giới có vòng eo bình thường chiếm đa số $74,7 \%$.

\subsection{Nồng độ Testosterone của nhóm nghiên cứu.}

Bảng 6. Nồng độ Testosterone của nhóm nghiên cứu

\begin{tabular}{|c|c|}
\hline & Giá trị \\
\hline Testosterone toàn phần $(\mathbf{n m o l} / \mathbf{l})$ & $16,64 \pm 6,90$ \\
$\overline{\mathbf{X}} \pm \mathbf{S D}$ & $(3,88 \div 36,62)$ \\
$(\mathbf{m i n}-\mathbf{m a x})$ & \\
$\mathbf{N}=\mathbf{7 9}$ & \\
\hline
\end{tabular}

Nhận xét: Nồng độ testosterone của nhóm đối tượng nghiên cứu bao gồm 79 nam giới trong độ tuổi từ 50 đến 60 tuổi là $16,64 \pm 6,90 \mathrm{nmol} / 1$, với nồng độ testosterone thấp nhất là 3,88 nmol/1, và cao nhất $36,62 \mathrm{nmol} / 1$.

Bảng 7. So sánh nồng độ testosterone ở nhóm có $\mathrm{ADAM}(+)$ và ADAM (-)

\begin{tabular}{|c|c|c|c|}
\hline & $\begin{array}{c}\text { ADAM (+) } \\
\mathbf{n = 6 6}\end{array}$ & $\begin{array}{c}\text { ADAM (-) } \\
\mathbf{n = 1 3}\end{array}$ & $\mathbf{p}$ \\
\hline $\begin{array}{c}\text { Testosterone (nmol/1) } \\
\overline{\mathrm{X}} \pm \mathrm{SD}\end{array}$ & $16,17 \pm 7,01$ & $18,99 \pm 5,98$ & 0,18 \\
\hline
\end{tabular}

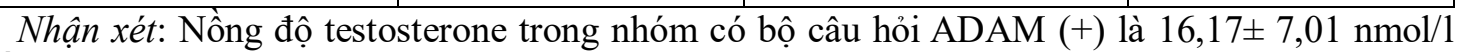
thấp hơn nhóm có $\mathrm{ADAM}(-)$ là $18,99 \pm 5,98 \mathrm{nmol} / \mathrm{l}$. Tuy nhiên sự khác biệt này là không có ý nghĩa thống kê với $p>0,05(\mathrm{p}=0,18)$ (T- test). Trong nhóm nghiên cứu của chúng tôi có 14 nam giới có nồng độ testosterone $<10 \mathrm{nmol} / 1$, chiếm tỷ lệ $17,7 \%$. Trong số này, tất cả $100 \%$ đều có kết quả bộ câu hỏi ADAM (+).

3.3. Nhận xét một số yếu tố liên quan đến nồng độ testosterone máu ở nhóm đối tượng nghiên cứu.

\subsubsection{Hút thuốc lá, uống ruọu:}

Bảng 8. So sánh nồng độ testosterone ở giữa nhóm hút thuốc với không hút thuốc; giữa nhóm uống rượu với không uống rượu.

\begin{tabular}{|c|c|c|c|}
\hline & $\begin{array}{c}\text { Có hút thuốc } \\
\mathbf{n = 4 4}\end{array}$ & $\begin{array}{c}\text { Không hút thuốc } \\
\mathbf{n = 3 5}\end{array}$ & $\mathbf{p}$ \\
\hline $\begin{array}{c}\text { Testosterone (nmol/l) } \\
\overline{\mathrm{X}} \pm \mathrm{SD}\end{array}$ & $16,63 \pm 6,31$ & $16,65 \pm 7,67$ & 0.987 \\
\hline & $\begin{array}{c}\text { Có uống rượu } \\
(\mathbf{n = 5 7 )}\end{array}$ & $\begin{array}{c}\text { Không uống rượu } \\
(\mathbf{n = 2 2})\end{array}$ & $\mathbf{p}$ \\
\hline $\begin{array}{c}\text { Testosterone (nmol/l) } \\
\overline{\mathrm{X}} \pm \mathrm{SD}\end{array}$ & $15,77 \pm 6,94$ & $18,88 \pm 6,39$ & 0,073 \\
\hline
\end{tabular}

Nhận xét: Trong 79 nam giới thuộc nhóm nghiên cứu,không có sự khác biệt có ý nghĩa thống kê về nồng độ testosterone TP của nhóm hút thuốc với nhóm không hút thuốc và giữa nhóm uống rượu với không uống rượu với $\mathrm{p}>0,05$. 


\subsubsection{Tăng huyết áp}

Bảng 9. So sánh nồng độ testosterone ở nhóm có THA và không có THA

\begin{tabular}{|c|c|c|c|}
\hline & $\begin{array}{c}\text { Có THA } \\
(\mathbf{n = 2 3})\end{array}$ & $\begin{array}{c}\text { Không có THA } \\
(\mathbf{n = 2 2})\end{array}$ & $\mathbf{p}$ \\
\hline $\begin{array}{c}\text { Testosterone (nmol/1) } \\
\overline{\mathrm{X}} \pm \mathrm{SD}\end{array}$ & $14,49 \pm 6,09$ & $17,52 \pm 7,07$ & 0,76 \\
\hline
\end{tabular}

Nhận xét: Nồng độ testosterone TP của nhóm có THA là thấp hơn nhóm không có THA, tuy nhiên sự khác biệt là không có ý nghĩa thống kê với $\mathrm{p}=0,76(>0,05)$

3.3.3. BMI, vòng eo, chỉ số eo/hông

Bảng 10.Mối tương quan giữa nồng độ testosterone với BMI, vòng eo, chỉ số eo/hông

\begin{tabular}{|c|c|c|}
\hline & Testosterone & $\boldsymbol{p}$ \\
\hline BMI & $-0,336^{*}$ & 0,002 \\
\hline Vòng eo & $-0,324^{*}$ & 0,004 \\
\hline Chỉ số eo/hông & $-0,195$ & 0,084 \\
\hline
\end{tabular}

Chú thích: dấu*: sự tương quan có ý nghĩa thống kê.

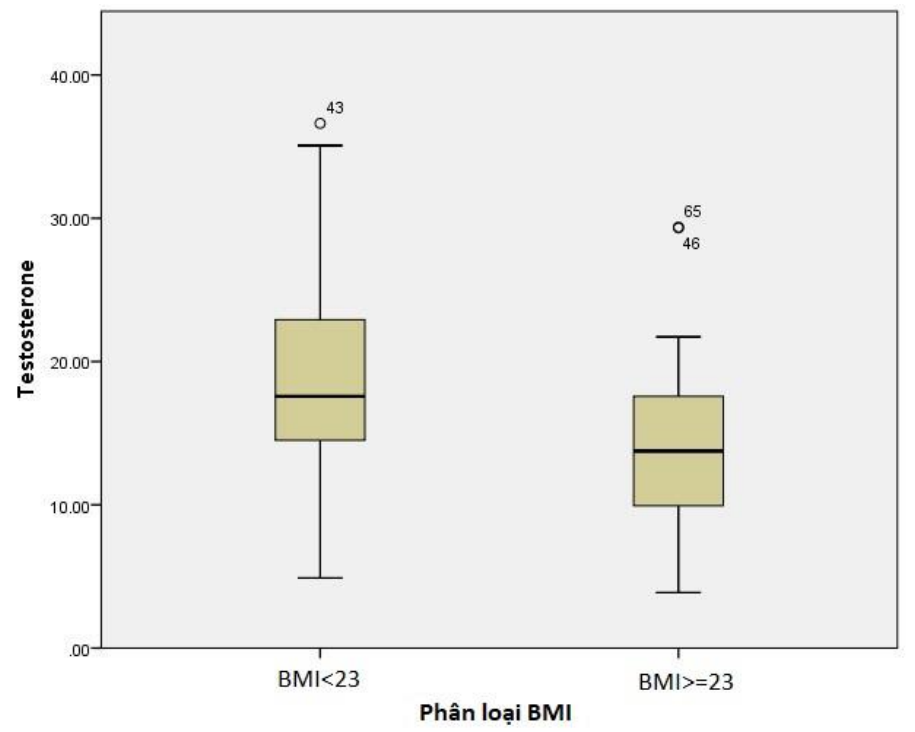

Biểu đồ 1. So sánh nồng độ testosterone ở nhóm có $\mathrm{BMI}<23$ và $\mathrm{BMI} \geq 23$

Nhận xét: Trong nhóm đối tượng nghiên cứu thì nhóm nam giới thừa cân,béo phì (BMI $\geq 23)$ có nồng độ testosterone máu $14.17 \pm 5.66(\mathrm{nmol} / \mathrm{l})$ thấp hơn bệnh nhân có BMI bình thường $(\mathrm{BMI}<23) 18,50 \pm 7.21(\mathrm{nmol} / \mathrm{l})$. Sự khác biệt có ý nghĩa thống kê với $\mathrm{p}<0,05(\mathrm{p}=0,005)$ (Ttest).Bên cạnh đó, trong nhóm đối tượng nghiên cứu chúng tôi còn thấy có sự tương quan nghịch biến có ý nghũa thống kê giữa nồng độ testosterone máu và $\mathrm{BMI}$ với $\mathrm{r}=-0.336$ với $\mathrm{p}=0.002$ (Pearson-test).

Bảng 11. So sánh nồng độ Testosterone dựa trên phân loại vòng eo và chỉ số eo/hông (WHR)

\begin{tabular}{|c|c|c|c|}
\hline & \multicolumn{2}{|c|}{ Vòng eo $(\mathbf{n = 7 9})$} & \multirow{2}{*}{$\boldsymbol{p}$} \\
\cline { 2 - 3 } & $<90(\mathbf{n = 5 9})$ & $\mathbf{2 9 0}(\mathbf{n}=\mathbf{2 0})$ & \multirow{2}{*}{0.016} \\
\hline Testosterone $(\mathrm{nmol} / \mathrm{l})$ & $17,71 \pm 7,08$ & $13,46 \pm 5,28$ & \\
$\overline{\mathrm{X}}_{ \pm \mathrm{SD}}$ & & & \\
\hline
\end{tabular}




\begin{tabular}{|c|c|c|c|}
\hline \multirow{2}{*}{} & \multicolumn{2}{|c|}{ Chỉ số eo/hông (n=77) } & \multirow{2}{*}{} \\
\cline { 2 - 3 } & $\mathbf{< 0 , 9}(\mathbf{n = 2 2})$ & $\mathbf{0 0 , 9}(\mathbf{n = 5 7 )}$ & \\
\hline $\begin{array}{c}\text { Testosterone (nmol/1) } \\
\bar{X} \pm \mathrm{SD}\end{array}$ & $17,55 \pm 6,78$ & $16,28 \pm 6,96$ & 0 \\
\hline
\end{tabular}

Ngoài ra,trong nhóm đối tượng nghiên cứu chúng tôi còn thấy có sự tương quan nghịch biến có ý nghĩa thống kê giữa nồng độ testosterone máu với vòng eo $(\mathrm{r}=-0,324$ với $\mathrm{p}=0,004)$.

Không có sự tương quan có ý nghĩa thống kê giữa nồng độ testosterone toàn phần với chỉ số eo/hông (WHR) (r=-0,195, p= 0,084) (Pearson-test).

Nồng độ testosterone ở nhóm có vòng eo lớn $(\geq 90 \mathrm{~cm}) 13,46 \pm 5,28$ (nmol/l) thấp hơn đáng kể nhóm có vòng eo bình thường $(<90 \mathrm{~cm})$ là $17,71 \pm 7,08(\mathrm{nmol} / 1)$ với $\mathrm{p}<0,05$, tuy nhiên, không có sự khác biệt có ý nghĩa thống kê giữa nồng độ testosterone của nhóm có chỉ số eo/ hông bình thường $(<0,9)$ và nhóm có chỉ số eo/ hông lớn $(\geq 0,9)$.

\subsubsection{Các thành phần lipid máu}

Bảng 12. Mối tương quan giữa nồng độ testosterone với từng thành phần lipid máu

\begin{tabular}{|c|c|c|c|}
\hline & Testosterone & $\boldsymbol{p}$ & \\
\hline Cholesterol TP & $-0,354^{*}$ & 0,001 & Pearson - test \\
\hline LDL-C & $-0,295^{*}$ & 0,008 & Pearson - test \\
\hline HDL-C & 0,144 & 0,207 & Spearman- test \\
\hline Triglyceride & $-0,333^{*}$ & 0,032 & Spearman- test \\
\hline
\end{tabular}

Chú thích: dấu*: sự tương quan có ý nghĩa thống kê.
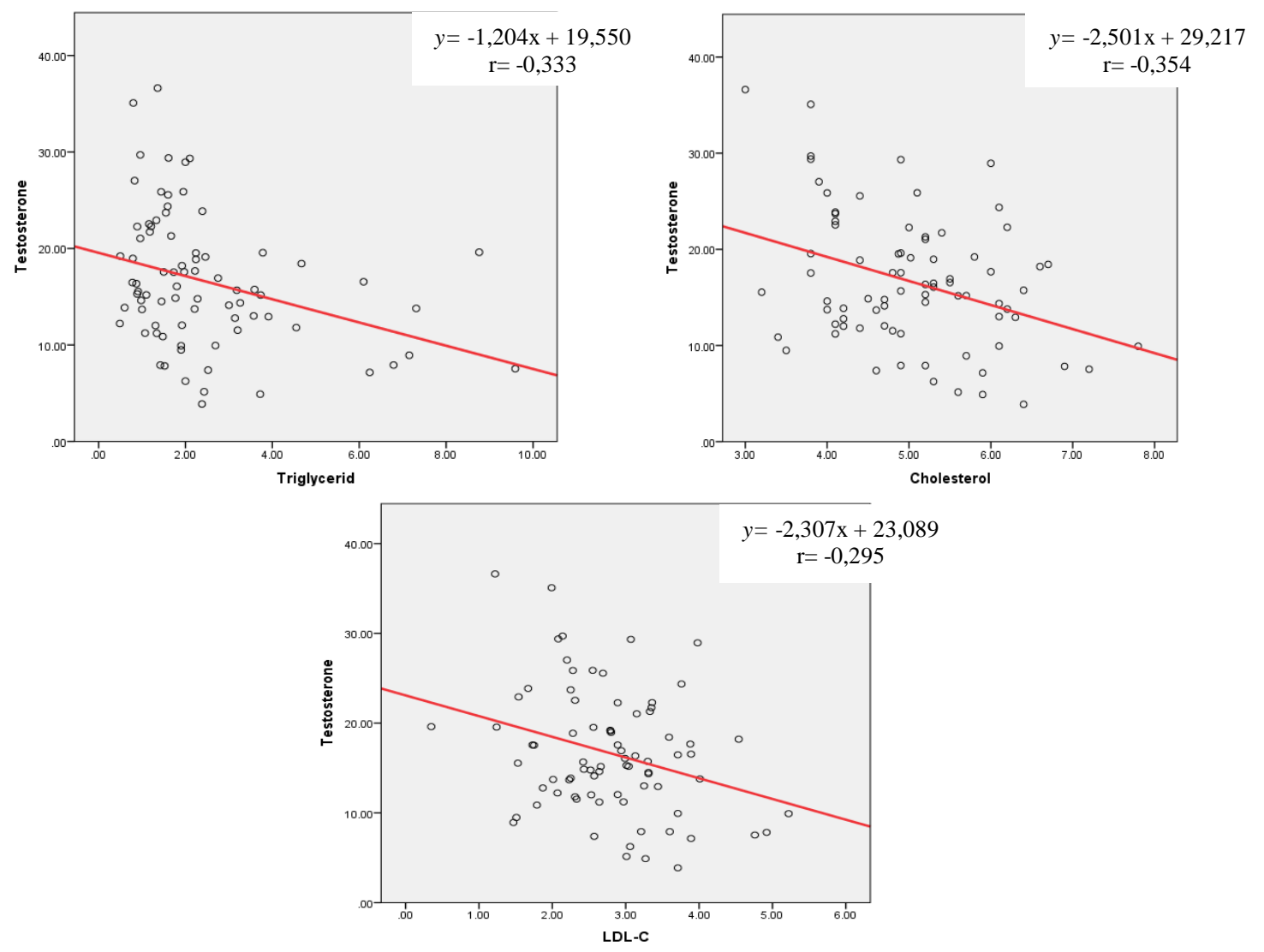

Biểu đồ 3.4. Sự tương quan giữa nồng độ testosterone máu với các thành phần lipid máu 
Nhận xét: Trong nhóm đối tượng nghiên cứu nồng độ testosterone có sự tương quan nghịch biến với nồng độ, Triglyceride (Spearman- test), Cholesterol (Pearson - test) vàLDL-C (Pearson - test) (với $r=-0,333, r=-$ $0,354$ và $\mathrm{r}=-0,295, \mathrm{p}<0,05)$. Chúng tôi chưa thấy sự tương quan có ý nghĩa thống kê giữa nồng độ testosterone với nồng độ HDL-C (Spearman-test).

\section{BÀN LUẬN \\ 4.1. Đặc điểm chung của đối tượng nghiên cứu}

Trong nghiên cứu này, đối tượng là những nam giới đi khám tại khoa Khám bệnh theo yêu cầu tại Bệnh viện Bạch Mai trong độ tuổi từ 50-60, với độ tuổi trung bình là của chúng tôi, tuổi trung bình 54.90ะ3.49. BMI trung bình của nhóm đối tượng nghiên cứu là $22,6 \pm 2,8$, trong đó số có $\mathrm{BMI}$ ở mức thừa cân béo phì chiếm gần $1 / 2(43,0 \%)$, vòng eo trung bình của nhóm đối tượng nghiên cứu là $83,10 \pm 8,11 \mathrm{~cm}$, trong đó số lượng nam giới có vòng eo bình thường chiếm đa số $74,7 \%$.

4.2. Nồng độ testosterone của nhóm đối tượng nghiên cứu.

Nồng độ testosterone máu toàn phần của

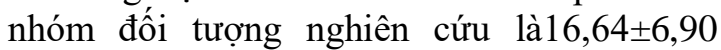
nmol/l, với nồng độ testosterone thấp nhất là $3,88 \mathrm{nmol} / 1$, và cao nhất $36,62 \mathrm{nmol} / 1$. Kết quả của chúng tôi cũng khá tương đồng với kết quả trong nghiên cứu của Martinez Jabaloyas năm 2008 trên 230 nam giới từ độ tuổi 50 trở lên tại Tây Ban Nha [3].

Trong nghiên cứu của chúng tôi, nồng độ testosterone toàn phần giữa nhóm hút thuốc và không hút thuốc là không có sự khác biệt. Còn ở nhóm uống rượu và nhóm tăng huyết áp thì nồng độ testosterone toàn phần thấp hơn so với nhóm còn lại tương ứng, lần lượt là: $15,77 \pm 6,94$ so với $18,88 \pm 6,39 ; 14,49 \pm$ 6,09 so với $17,52 \pm 7,07$ tuy nhiên sự khác biệt này là không có ý nghĩa thống kê với p> 0,05 .

Nồng độ testosterone của nhóm có ADAM dương tính là $16,17 \pm 7,01(\mathrm{nmol} / 1)$ thấp hơn

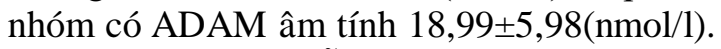
Tuy nhiên do cỡ mẫu quá nhỏ nên sự khác biệt chưa có ý nghĩa thống kê với p>0,05. Chúng tôi cũng nhận thấy trong nhóm nghiên cứu có 14 bệnh nhân có nồng độ testosterone máu toàn phần $<10 \mathrm{nmol} / 1$, trong số này thì $100 \%$ bệnh nhân này đều có kết quả $\mathrm{ADAM}$ dương tính.

Kết quả này cho thấy bộ câu hỏi ADAM có độ nhạy rất cao và độ đặc hiệu rất thấp nên chủ yếu dùng để sàng lọc không dùng để chẩn đoán bệnh.

Kết quả nghiên cứu của chúng tôi cũng cho thấy có mối tương quan nghịch biến giữa nồng độ testosterone máu toàn phần với $\mathrm{BMI}$, vòng bụng, với hệ số tương quan lần lượt là $(\mathrm{r}$ $=-0,336, \mathrm{p}=0,002)$ và $(\mathrm{r}=-0,324, \mathrm{p}=0,004)$. Kết quả này của chúng tôi cũng tương tự với nghiên cứu của Grosman trên 660 nam giới ở Argentina với nồng độ testosterone toàn phần tương quan nghịch với BMI $(\mathrm{r}=-0,29$, $\mathrm{p}$ $<0,0001)$ và với vòng bụng $(\mathrm{r}=-0,26$, $\mathrm{p}<0,0001)$ [4].

Một điểm quan trọng nữa trong nghiên cứu này, cũng cho thấy nồng độ testosterone máu toàn phần cũng có mối tương quan nghịch biến với nồng độ triglyceride máu, cholesterol máu và $L D L-C$. Nghiên cứu này của chúng tôi cũng phù hợp với nghiên cứu của tác giả Grosman của Argentina [4] và tác giả Zhang J của Trung Quốc [5].

\section{KẾT LUẬN}

Nồng độ testosterone toàn phần ở nhóm đối tượng nghiên cứu là nam giới từ $50-60$ tuổi là $16,64 \pm 6,90$. Chúng tôi chưa tìm thấy sự khác biệt về nồng độ testosterone toàn phần giữa nhóm có $\mathrm{ADAM}(+)$ và $\mathrm{ADAM}(-)$.

Nồng độ testosterone máu toàn phần tương quan nghịch biến với nồng độ Triglycerid, Cholesterol và LDL-C. Chưa thấy sự tương quan có ý nghĩa giữa nồng độ testosterone máu toàn phần với và HDL-C.

Ngoài ra, nồng độ testosterone máu toàn phần còn tương quan nghịch biến với $\mathrm{BMI}$ và vòng eo.

Trong nghiên cứu này, chưa tìm thấy sự khác biệt có ý nghĩa thống kê về nồng độ testosterone của các nhóm có THA, uống rượu và hút thuốc. 


\section{TÀI LIÊU THAM KHẢO}

1. Quân ĐT. Bệnh lý tuyến sinh dục nam. Bệnh nọi tiết chuyển hóa. 2015:403-421.

2. Jones TH. Advances in the management of testosterone deficiency. Introduction. Frontiers of hormone research. 2009;37:1-4. doi: 10.1159/000175838.

3. Martinez Jabaloyas JM, Queipo Zaragoza A, Ferrandis Cortes C, Queipo Zaragoza JA, Gil Salom M, Chuan Nuez P. [Changes in sexual hormones in a male population over 50 years of age. Frequency of low testosterone levels and risk factors]. Actas Urol Esp. Jun 2008;32(6):603-610. doi: 10.1016/s02104806(08)73895-6.
4. Grosman H, Rosales M, Fabre B, et al. Association between testosterone levels and the metabolic syndrome in adult men. Aging Male. Sep 2014;17(3):161165. doi: $\quad 10.3109 / 13685538$. 2014.913561.

5. Zhang J, Huang X, Liao M, et al. Both total testosterone and sex hormonebinding globulin are independent risk factors for metabolic syndrome: results from Fangchenggang Area Male Health and Examination Survey in China. Diabetes/metabolism research and reviews. Jul 2013;29(5):391-397. doi: 10.1002/dmrr.2405. 